\title{
EXPERIMENTAL STUDY OF RAILWAY BALLAST CONSOLIDATION INHOMOGENEITY UNDER VIBRATION LOADING
}

\author{
${ }^{1}$ Mykola SYSYN ${ }^{*}{ }^{2}$ Vitalii KOVALCHUK, ${ }^{3}$ UIf GERBER \\ ${ }^{4}$ Olga NABOCHENKO, ${ }^{5}$ Andriy PENTSAK

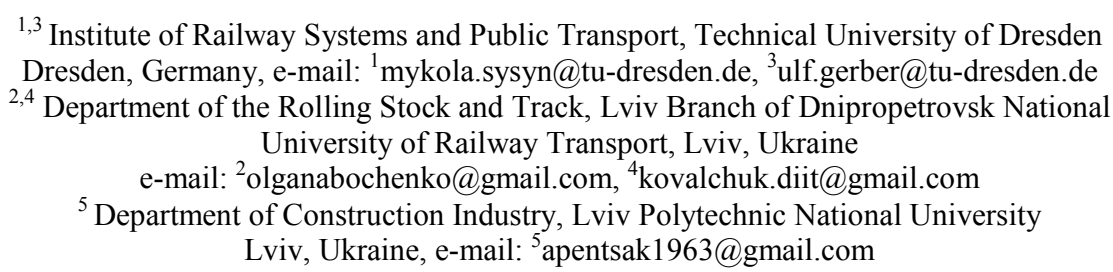

Received 13 February 2019; accepted 22 May 2019

\begin{abstract}
Railway ballast tamping is one of the cost-expensive renewal and maintenance works of railway superstructure. The quality of ballast consolidation influences its resistance to residual deformations and long-term deterioration of track geometry. The process of ballast compaction along the sleeper under the vibration loading is complex and depends on many factors. The ballast flow processes under the vibration loading can produce both consolidation and un-consolidation of ballast material. The present study is devoted to the experimental investigation of ballast consolidation inhomogeneity. The method of ballast local consolidation measurement is proposed. The method is based on the velocity of impact wave propagation that is measured with device. The application of modern microcontroller and sensor techniques provided simple and reliable multi-point velocity measurements in a ballast layer. That enables well enough spatial resolution of ballast consolidation inhomogeneity. The measurement analysis has shown more than 4 times higher consolidation under the sleeper center than for unconsolidated ballast.
\end{abstract}

Keywords: Railway ballast, Tamping, Consolidation, Impulse wave propagation, Nondestructive measurement, Ballast inhomogeneity

\section{Introduction}

Railway transport operation, train velocities and traffic reliability depend on geometrical quality of railway track. One of the main elements of railway track that most affects the geometrical quality is the railway ballast. The initial track irregularities

${ }^{*}$ Corresponding Author 
appear usually due to inhomogeneous settlements of ballast layer. The number and dimensions of track irregularities limit the track geometry lifecycle with the corrective maintenance works. The typical ballast tamping cycles amount to 40-70 million tons. Therefore the cycles are the shortest of all other maintenance cycles of railway track [1]. The lifecycle costs for a high-density main line of west European railways are distributed between $20 \%$ maintenance costs, $33 \%$ operational hindrance costs and $47 \%$ of depreciation costs [1]. The costs share of ballast construction is about a third of the overall track superstructure [2]. Despite of high mechanized and economic efficient ballast maintenance machinery the share of their costs is still high. Due to relative often and cost expensive maintenance for ballast tamping and cleaning works, the share of ballast can reach up to $60 \%$ in maintenance and operational hindrance costs [3]. Nevertheless, ballasted track offers a lot of benefits compared to the ballast-less slab track. Although the slab track almost fully eliminates the costs for track geometry correction, but the enormous costs for slab superstructure and high demands for subgrade, makes it low competitive to the ballasted track in European traffic conditions. Quite contrary, for intensive traffic of Asian railways with much ratio of maintenance and operational hindrance costs, slab track offers cost effective option to ballasted track. The main advantage of ballasted track is quick and cost-efficient construction and maintenance. The central drawback is quick geometry deterioration.

All the pros and contra of ballasted railway track arise from mechanical characteristics of ballast material. The contradictory requirements are set for ballast layer material. On the one hand, it should be as possible fluid to receive the form during maintenance works. On the other hand, is should retain the form for the long time during the operation. The most important mechanical characteristics of ballast material, that determines its property to resist the residual deformations is the degree of consolidation. The control of the ballast consolidation during track construction and following operation provides a wide range of opportunities for geometry deterioration prediction and corrective maintenance planning. The knowledge how the consolidation of ballast layer influences its short and long time resistance could offer many opportunities for optimization of tamping machines and track construction.

The problem of ballast consolidation and ballast quality estimation is presented in many recent studies [4]-[8]. The influence of initial ballast consolidation, subgrade stiffness, vibrational interaction etc. on long-term inhomogeneous ballast settlements is studied in [9]-[11]. A review of experimental methods for railway ballast rheology and degradation study is given in [12]. The influence of vibration characteristic analysis of ballast with different aspect ratios on ballast settlements is presented in [13]. Track geometry deterioration taking into account the influence of rail joints and other factors is studied in [14], [15].

Experimental investigation of sleeper settlements for fresh and fouled ballasts after tamping works is presented in [16]. Theoretical analysis of influence of different maintenance methods on railway ballast compaction is shown in [17]. It is remarkable that the solid fraction criterion of compaction effectiveness varies in low range about $1 \%$ from unconsolidated to consolidated ballast. Simulation of inhomogeneous ballast settlements in track and common crossing that takes into account ballast consolidation is presented in [18], [19]. 
Much better opportunities for experimental investigation of railway ballast layer present geotechnical methods. A wide review of non-destructive experimental methods with application to railway track-bed ballast is presented in [20]. The modern seismotomographic methods Spectral Analysis Surface Waves (SASW) and Multichannel Analysis of Surface Waves (MASW) [21], [22], which are used for subgrade diagnostics, are potentially applicable for investigation of ballast layer. Application of non-destructive methods, like ground-penetrating radar for monitoring of transport structures is presented in [23].

The possibilities of applying the modern statistical methods for the analysis of multivariate data of acceleration sensors are discussed in [24]. Machine learning methods like supervised and unsupervised clustering are proposed in experimental study [25] to find out the spectral features of ballast consolidation. Application of modern statistical learning methods for interpretation of multivariate, dynamical measurements offers many opportunities for non-destructive measurements of ballast layer. Modern microcontroller and sensor techniques offer new ways for development of new diagnostic methods and devices for ballast layer condition monitoring.

The present paper deals with experimental investigation of ballast consolidation. The measurements of ballast consolidation are carried out with seismic measurement of elastic wave propagation. A measurement device for sound and acceleration measurement and analysis was developed for the aim. Ballast consolidation distribution along the sleeper after experimental testing with vibration loading is estimated.

\section{Measurement method and laboratory test}

Ballast consolidation measurement is carried out with non-destructive seismic method that is based on analysis of elastic wave propagation. The simple kinematic interpretation that is based on wave Time of Flight (ToF) measurement is used for experimental ballast compaction determination. The impact generation and multipoint sound and 2-axial acceleration measurements are produced with developed device. The simplified scheme of measurement device is shown in Fig. 1.

The impact generation control and wave sensing information acquisition is processed with programmable MicroController Unit (MCU). The developed firmware digitally controls 3 electrodynamic shakers via motor shield powering. The shakers are positioned over the ballast layer surface to induce the impact vibration that is recorded with a set of sensors. The shaker start and finish is additionally controlled with digital channels of MCU. Wave sensing is performed with Micro-Electro-Mechanical Systems (MEMS) microphones and 3g acceleration sensors. The 8 sensor pairs are placed under the ballast layer in special vibration isolated boxes. The analogous information of the acceleration sensor set is digitalized with 13 bit Analog Digital Converter (ADC) of slave MCU in $15 \mathrm{kHz}$ sample rate. The signals are saved on Secure Digital (SD) card with processing indication on Thin-Film Transistor (TFT) module. The microphone signals are pre-processed before coming to $\mathrm{MCU}$ in digital with comparator set. Only the information about ToF to microphone is saved on SD with MCU. This way of microphone information processing provides many advantages compared to acceleration measurement. The main advantages are that MEMS microphones are more sensitive 
than accelerometer. Quick digitalization with $300 \mathrm{kHz}$ comparator frequency provides much more accurate time resolution. Additionally, the measurement concept with microphones provides simultaneous up to 48 multi-sensor measurements with one developed system that is important for the space resolution. However, the measurement with microphones has also disadvantages: no separation on pressure and shear waves, no dynamical interpretation is possible. The reason of simultaneous sound and vibration measurements is the validation of results and substantiation of ballast consolidation measurement based on multi-sensor microphone principle. The firmware program includes time synchronization with time server, sensor testing, series of 12 impacts for each sensor with starting time fixation, synchronous sound and acceleration measurements, pre-processing and analysis with results indication and saving.

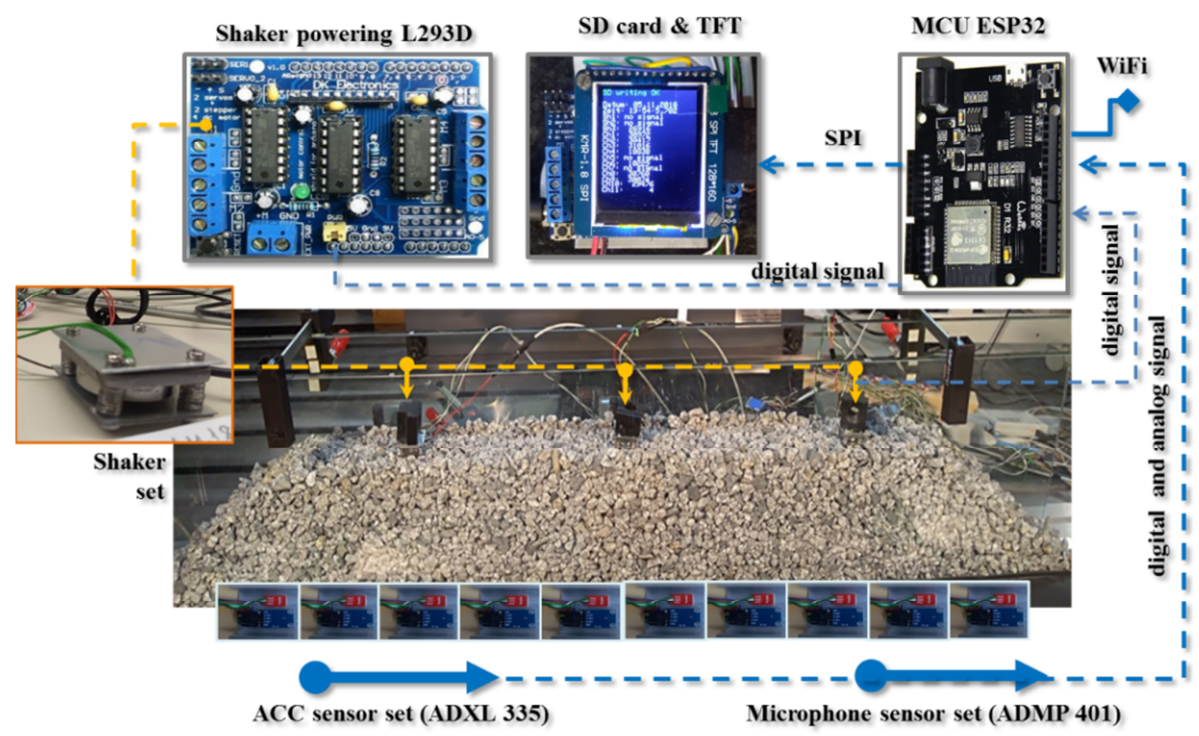

Fig. 1. Principal scheme of measurement device

The laboratory tests were done on physical model of ballast layer that corresponds to real ballast layer in scale 1:2.5 (Fig. 2). The experimental setup is a ballast box $1.0 \times 0.17 \times 0.33 \mathrm{~m}$ filled with layer $0.27 \mathrm{~m}$ of granite gravel of fraction $16 \mathrm{~mm}$. The long side walls are transparent thick glass plates to observe the ballast particle movement. The short side walls are movable in experiment. The bottom floor is equipped with a longitudinal raw of acceleration and sound sensors. Dynamic loading is carried out by a servo-hydraulic test machine ZWICK HB 160. The loading of machine is concentrated on a stiff H-beam with bottom $1.0 \times 0.10 \mathrm{~m}$ area that corresponds to a railway sleeper. The vertical loading on the sleeper is controlled and its movement is measured.

The experiment includes 3 loading phases: 
- \#1 - calibration loading: unconsolidated ballast specimen is limited on the both sides to provide the calibration measurements, the loading is static $0.5 \mathrm{kN}$;

- \#2 - operational loading: ballast specimen is free on the both sides with ballast slopes, the loading is dynamic in range $0.5 \mathrm{kN}-9.5 \mathrm{kN}$ with harmonic frequency $1 \mathrm{~Hz}$;

- \#3 - tamping loading: ballast specimen is free on the both sides with ballast slopes, the loading is dynamic in range $0 \mathrm{kN}-15 \mathrm{kN}$ with harmonic frequency $40 \mathrm{~Hz}$, the number of cycles is 1000 .

Fig. 2 shows the loadings and the deformations in all 3 cycles. After the phase \#1 no deformations of ballast layer were observed. In phase \#2, after releasing the both short walls, the settlements reach $6.7 \mathrm{~mm}$ in 25 loading cycles. Some stabilization is observed. In phase \#3, with free slopes and ballast shoulders, the settlements reach $19 \mathrm{~mm}$ in 1000 loading cycles. Almost no stabilization is observed. The measurement of ballast consolidation with developed device is carried out before the beginning of each cycle.
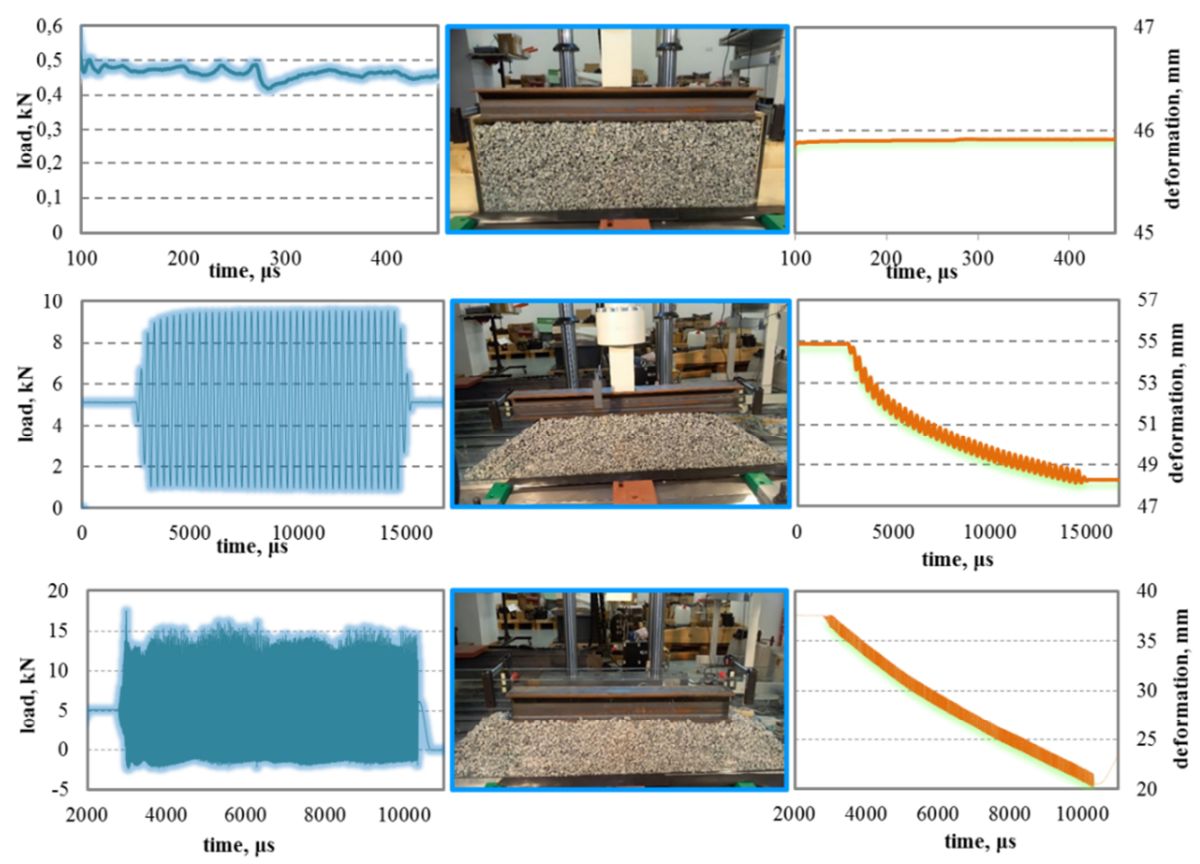

Fig. 2. Loading and deformations of ballast layer (top: phase \#1, middle: phase \#2 and down: phase \#3)

\section{Measurement interpretation and analysis of results}

The velocity of wave propagation is used as a measure of ballast compaction estimation. Similar estimation way is usually used in geophysics [23]-[26]. The wave 
velocity in gravel depends on its elastic properties and density that are proportional to the number of contacts between the particles i.e. compactness or consolidation. The time of wave front propagation from each shaker to nearest sensors is measured and together with known distances, the pressure wave velocity is determined. Accelerometers measure additionally pressure and shear velocities. Fig. 3 shows the distribution of sensors sets to the shaker and distance calculation scheme.

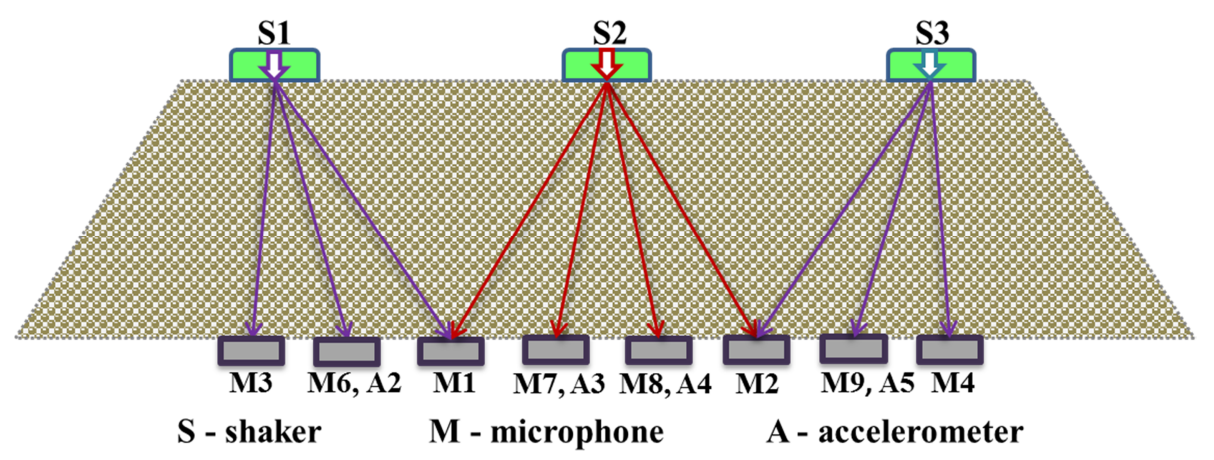

Fig. 3. The scheme for determining the distance between the shaker and sensors

The measurements of ballast layer consolidation are performed before each loading phase. Each phase corresponds to different consolidation of ballast layer. The sleeper is removed before each measurement to install the shakers. The results of wave velocities calculation for 3 ballast zones and 3 experiment phases are presented in Fig. 4.
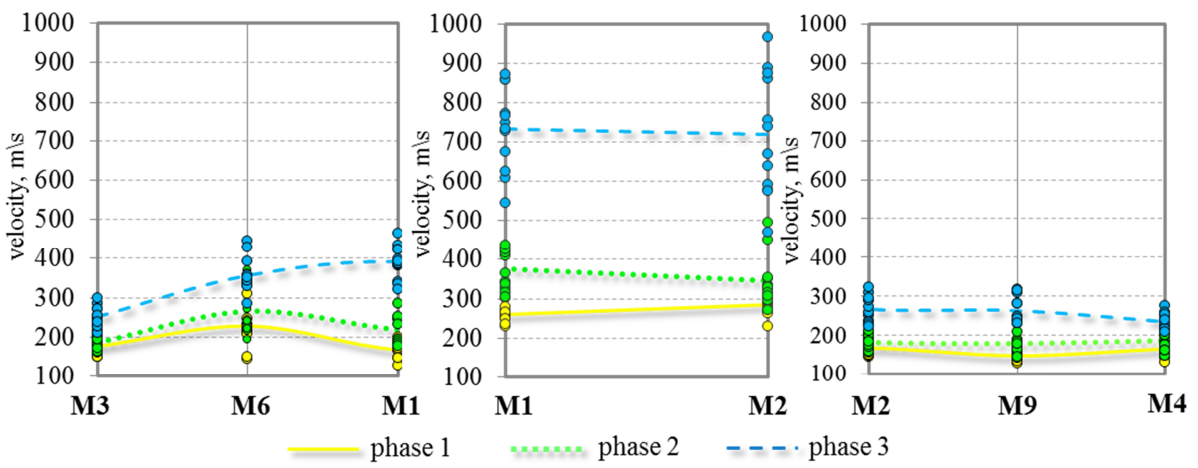

Fig. 4. The velocities of wave propagation for shaker S1 (left), S2 (middle), S3 (right)

The ballast layer under the central shaker S2 (Fig. 4, middle) shows much higher consolidation growth than those under the both sides of the sleeper (Fig. 4, left, right). The consolidation in initial phase is approximately the same and varies in range $150-250 \mathrm{~m} / \mathrm{s}$. The maximal velocity reached under the sleeper middle part is $732 \mathrm{~m} / \mathrm{s}$. 
However, the random variation of the velocities is high and amounts about to $25 \%$ standard deviation of the middle value. The average velocity in a left zone is for the maximal consolidated state is $340 \mathrm{~m} / \mathrm{s}$ and in the right $-280 \mathrm{~m} / \mathrm{s}$. The relative low growth of compaction under the sleeper ends can be explained with the intensive flow of ballast under the vibration loading.

The left and right diagrams in Fig. 4 show some growth of the velocities for the sensors closer to the sleeper, due to consolidation growth under the central part of sleeper. The velocities sensors M6 and M2 correspond to inclined wave path (Fig. 3) that could go through different consolidated zones. It could cause some averaging of velocity estimation for inclined wave rays. Therefore, for the following considerations, only the closest to shaker sensors M3 and M4 are taken into account. The generalization of wave velocity for the whole ballast layer is depicted on Fig. 5. The appended two external points of the ballast layer correspond to the initial unconsolidated state in phase \#1. The interpolation with spline average wave velocity shows symmetric distribution along the sleeper with maximum in the central zone.

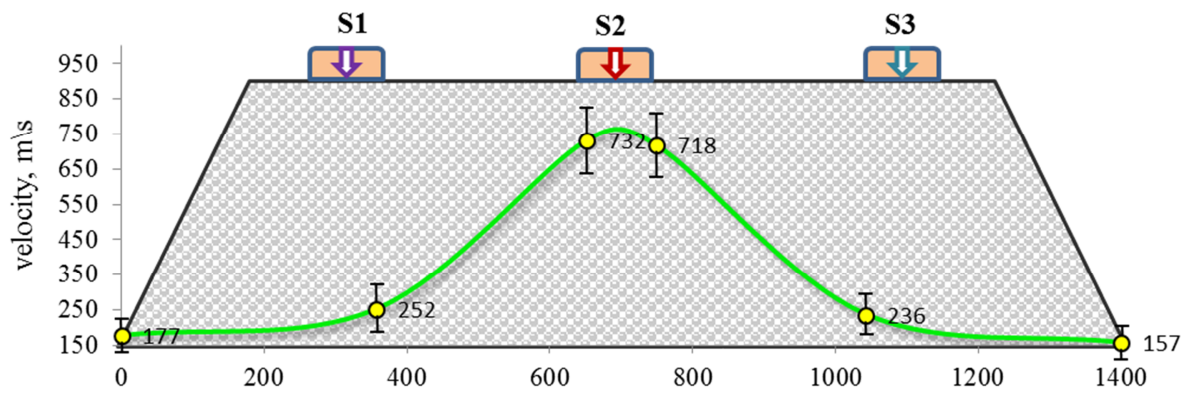

Fig. 5. The wave velocity distribution along the sleeper

The variation of average wave velocities in experiment is in range from $157 \mathrm{~m} / \mathrm{s}$ for initial unconsolidated ballast to $732 \mathrm{~m} / \mathrm{s}$ for maximal consolidation reached in experiment. The values correspond to the values range from reference books [27] for sediment rocks.

The estimation of ballast consolidation is considered as a percentage value of the wave velocity from the maximal velocity reached. Fig. 6 shows the ballast consolidation distribution along the sleeper. The maximal consolidation reached is almost 4 times higher than in the initial unconsolidated state. The consolidation under the sleeper ends is about a third from the maximal value. Thereby the standard deviation is about $25 \%$ of the mean value. Thus, consolidation parameter that is based on wave ToF has much better coefficient of determination than the methods based on the solidity or volume estimation.

The lower ballast consolidation under the sleeper is explained with the ballast flow and shear deformations causing ballast particle mixing and un-consolidation. The aim of ballast tamping and stabilization works is to produce the highest and at the same time homogenous consolidation. Evidentially, only the vertical vibrational loading cannot provide the homogenous consolidation of ballast under the sleeper. This effect is taking 
into account in many ballast-tamping machines by equipping them with additional side vibrational plates [28]. However, the efficiency of the working mode (loading and vibration) of the side vibrational plates is still unknown.

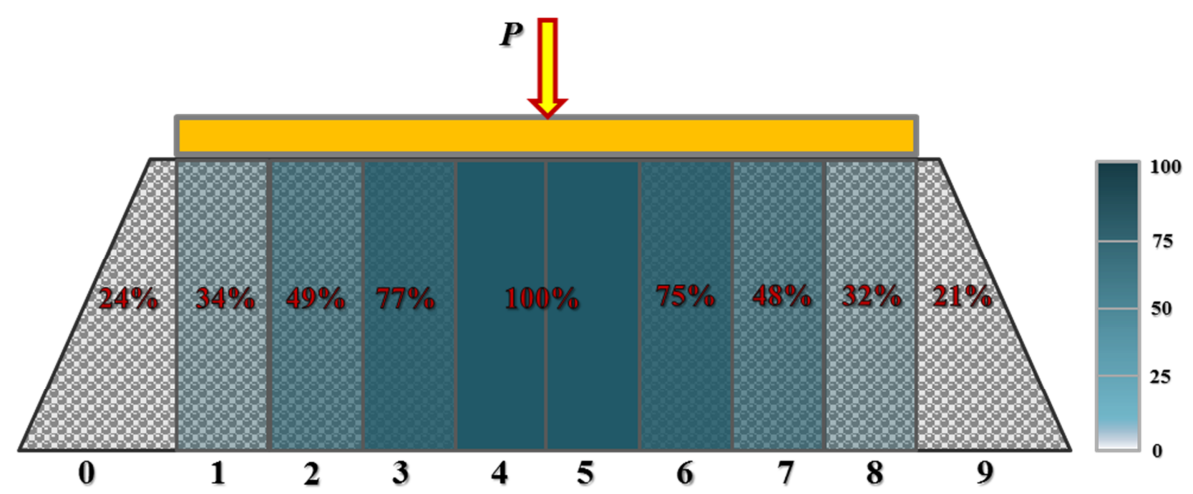

Fig. 6. The distribution of ballast consolidation along the sleeper

\section{Summary and subsequent studies}

The paper deals with the study of the processes of the railway ballast consolidation under the vibration loading. The measurements of ballast consolidation with developed non-destructive method have shown a high inhomogeneity of ballast consolidation along the sleeper. The methods used are the simplest but at the same time are based on reliable geophysical principle of determining the mechanical properties of soils. The methods completely meet the requirements to laboratory experimental measurements. However, the in-situ measurements of ballast compaction require the application of more advanced techniques with sensors location on the surface of ballast layer and measurement of surface waves. The modern low-cost microcontroller and sensor technologies could provide the target specific development of mobile or autonomous measurement devices for multipoint on-line big data acquisition. The modern machine and deep learning methods could afford the efficient utilization of the collected information.

The presented study has shown quite different consolidation of ballast layer along the sleeper, even after vibration loading. This indicates the possibilities of further optimization ways of ballast layer. The developed measurement method of ballast consolidation distribution under the sleeper offers good opportunities for the practical optimization of ballast tamping technology as well as the superstructure optimization. The optimization of ballast tamping that takes into account the ballast consolidation distribution could facilitate the search of technical solutions for ballast saving and at the same time efficient tamping.

The consolidation of ballast layer is considered along the sleeper and only for the vertical directions under the shakers. However, there was not used all the information from inclined wave rays, due to the difficulty of interpretation. Moreover, it could be 
supposed that the ballast compaction varies with the depth of ballast layer. The application of more advanced methods of seismic tomography could provide the improvement of consolidation estimation. Ballast consolidation has relationship with the elastic and strength properties of ballast material. The internal friction of railway ballast is determining its property to resist the long-term residual deformations. The research of the relation is a promising direction of the subsequent studies.

\section{References}

[1] Lichtberger B. Track compendium: formation, permanent way, maintenance, economics, Hamburg, Eurailpress, 2005.

[2] Gerber U. Design of railway superstructure, (in German) in Fendrich L., Fengler W., (Eds), Handbuch Eisenbahninfrastruktur, Springer, Vol. 2, 2013, pp. 39-64.

[3] Esveld C. Modern railway track (Vol. 385). Zaltbommel, The Netherlands, MRTproductions, 2001.

[4] Izvolt L., Harusinec J., Smalo M. Optimization of transition areas between ballast-less track and ballasted track in the area of the tunnel turecky vrch, Communications, Scientific Letters of the University of Zilina, Vol. 20, No. 3, 2018, pp. 67-76.

[5] Kovalchuk V., Kovalchuk Y., Sysyn M., Stankevych V., Petrenko O. Estimation of carrying capacity of metallic corrugated structures of the type multiplate mp 150 during interaction with backfill soil, Eastern-European Journal of Enterprise Technologies, Vol. 1, No. 1, (Vol. 91), 2018, pp.18-26.

[6] Fischer S. Breakage test of railway ballast materials with new laboratory method, Periodica Polytechnica, Civil Engineering, Vol. 61, No. 4, 2017, pp. 794-802.

[7] Plášek O., Hruzíková M., Svoboda R., Vendel J. Influence of under sleeper pads on track quality, Akustika, Vol. 23, No. 1, 2015, pp. 28-33.

[8] Fischer S., Juhász E. Railroad ballast particle breakage with unique laboratory test method, Acta Technica Jaurinensis, Architecture and Civil Engineering, Vol. 12, No. 1, 2019, pp. 26-54.

[9] Gerber U., Fengler, W. Settlement behaviour of ballast layer, (Setzungsverhalten des Schotters, in German) Eisenbahntechnische Rundschau, Vol. 4, 2010, pp. 170-175.

[10] Sysyn M., Gerber U., Kovalchuk V., Nabochenko O. The complex phenomenological model for prediction of inhomogeneous deformations of railway ballast layer after tamping works, Archives of Transport, Vol. 46, No. 3, 2018, pp. 91-107.

[11] Holtzendorff K. Investigation of the settlement behaviour of railway ballast and the void forming on railway tracks, (Untersuchung des Setzungsverhaltens von Bahnschotter und der Hohllagenentwicklung auf Schotterfahrbahnen, in German) PhD Thesis, Technische Universität Berlin, 2003.

[12] Guo Y., Markine V., Zhang X., Qiang W., Jing G. Image analysis for morphology, rheology and degradation study of railway ballast: A review, Transportation Geotechnics, Vol. 18, 2018, pp. 173-211.

[13] Wang B., Martin U., Rapp S. Vibration characteristic analysis of ballast with different aspect ratios by means of the discrete element method, Fourth Geo-China International Conference, Shandong, China, 25-27 July 2016, pp. 16-23.

[14] Németh A., Fischer S. Investigation of glued insulated rail joints with special fiber-glass reinforced synthetic fishplates using in continuously welded tracks, Pollack Periodica, Vol. 13, No. 2, 2018, pp. 77-86.

[15] Nagy R. Description of rail track geometry deterioration process in hungarian rail lines no. 1 and no. 140, Pollack Periodica, Vol. 12, No. 3, 2017, pp. 141-156. 
[16] Kumara J. J., Hayano K. Deformation characteristics of fresh and fouled ballasts subjected to tamping maintenance, Soils and Foundations, Vol. 56, No. 4, 2016, pp. 652-663.

[17] Ferellec J. F., Perales R., Nhu V. H., Wone M., Saussine G. Analysis of compaction of railway ballast by different maintenance methods using DEM, EPJ Web of Conferences, Vol. 140, 2018, paper No. 15032, pages 4.

[18] Nabochenko O., Sysyn M., Kovalchuk V., Kovalchuk Yu., Pentsak A., Braichenko S. Studying the railroad track geometry deterioration as a result of an uneven subsidence of the ballast layer, Eastern-European Journal of Enterprise Technologies, Vol. 1, No. 7(97), 2019, pp. 50-59.

[19] Sysyn M., Gerber U., Gruen D., Nabochenko O., Kovalchuk V. Modeling and vehicle based measurements of ballast settlements under the common crossing, European Transport, Vol. 71, 2019, pp. 1-19.

[20] Bold R. D. Non-destructive evaluation of railway tracked ballast, PhD Thesis, Institute for Infrastructure and Environment, School of Engineering, University of Edinburgh, 2011.

[21] Park C. B., Miller R. D., Ryden N. Roadside seismic survey utilizing traffic noise, Proceeding of the NDE (Non-Destructive Engineering) Conference on Civil Engineering, St. Louis, MO, USA, 14-18 August 2006, pp. 323-334.

[22] Sussmann T. R., Thompson H. B., Stark T. D., Wilk S. T., Ho C. L. Use of seismic surface wave testing to assess track substructure condition, Construction and Building Materials, Vol. 155, 2017, pp. 1250-1255.

[23] Zhang Q., Gascoyne J., Eriksen A. Characterisation of ballast materials in trackbed using ground penetrating radar, Part $1,5^{\text {th }}$ IET Conference on Railway Condition Monitoring and Non-Destructive Testing, Derby, UK, 29-30 November 2011, page 4.a.1.

[24] Sysyn M., Gruen D., Gerber U., Nabochenko O., Kovalchuk V. Turnout monitoring with vehicle based inertial measurements of operational trains: a machine learning approach, Communications - Scientific Letters of the University of Zilina, Vol. 21, No. 1, 2019, pp. $42-48$.

[25] Sysyn M., Nabochenko O., Gerber U., Kovalchuk V. Evaluation of railway ballast layer consolidation after maintenance works, Acta Polytechnica, Vol. 58, No. 6, 2019, pp. 1-16.

[26] Zhao D. Multiscale seismic tomography, Springer, 2015.

[27] Dahm T. Basics of geophysics, (Grundlagen der Geophysik, in German) - Lecture Notes, Potsdam: Deutsches GeoForschungsZentrum 2015.

[28] Marx L., Moßmann D. Working method for the maintenance of the superstructure, (Arbeitsverfahren für die Instandhaltung des Oberbaus, in German) Bahn Fachverlag Auflage, $7^{\text {th }}$ Ed, 2011. 